\title{
Inducible Nitric Oxide Synthase Isoform Is a Key Mediator of Leukostasis and Blood-Retinal Barrier Breakdown in Diabetic Retinopathy
}

\author{
Ermelindo C. Leal, ${ }^{1,2,3}$ Ayyakkannu Manivannan, ${ }^{4}$ Ken-Ichi Hosoya, ${ }^{5}$ Tetsuya Terasaki, ${ }^{6}$ \\ José Cunba-Vaz, ${ }^{1}$ António Francisco Ambrósio, ${ }^{1,2}$ and Jobn V. Forrester ${ }^{3}$
}

\begin{abstract}
Purpose. Nitric oxide (NO) is involved in leukostasis and bloodretinal barrier (BRB) breakdown in the early stages of diabetic retinopathy (DR), but it is unclear which NO synthase (NOS) isoforms are primarily involved. In this study, the authors aimed to clarify the involvement of constitutive (eNOS, nNOS) and inducible NOS (iNOS) isoforms and the mechanisms underlying NO-mediated leukostasis and BRB breakdown.
\end{abstract}

Methods. Diabetes was induced with streptozotocin for 2 weeks. Mice were treated with a NOS inhibitor, $N^{\mathrm{G}}$-nitro-Larginine methyl ester (L-NAME), which shows a preference for constitutive isoforms over iNOS. Vessel leakage was assessed with Evans blue. Leukostasis was quantified in flat-mounted retinas with confocal microscopy, in vivo with a scanning laser ophthalmoscope, and in vitro in a retinal endothelial cell line. ICAM-1, occludin, and ZO-1 levels were assessed by Western blot, flow cytometry, or immunohistochemistry. Nitrotyrosine content was assessed by immunohistochemistry.

RESUlts. Diabetes increased leukostasis within retinal vessels and BRB permeability, which were reduced by L-NAME. Similar effects were observed in diabetic iNOS knockout mice. In diabetic mouse retinas, ICAM-1 protein levels increased, whereas the immunoreactivity of tight junction proteins, occludin and ZO-1 decreased, in correlation with increased protein levels of all NOS isoforms. Those effects were prevented by L-NAME and also in diabetic iNOS knockout mice. High glucose and nitrosative/oxidative stress also increased leukostasis caused by ICAM-1 upregulation.

Conclusions. These results indicate that the iNOS isoform plays a predominant role in leukostasis and BRB breakdown. The mechanism involves ICAM-1 upregulation and tight junction protein downregulation. (Invest Ophthalmol Vis Sci. 2007;48: 5257-5265) DOI:10.1167/iovs.07-0112

From the ${ }^{1}$ Center of Ophthalmology of Coimbra, IBILI, Faculty of Medicine, and the ${ }^{2}$ Center for Neuroscience and Cell Biology, University of Coimbra, Coimbra, Portugal; ${ }^{3}$ Institute of Medical Sciences, Department of Ophthalmology, and ${ }^{4}$ Department of Radiology, University of Aberdeen, Aberdeen, United Kingdom; ${ }^{5}$ Graduate School of Medical and Pharmaceutical Sciences, University of Toyama, Toyama, Japan; ${ }^{6}$ Department of Molecular Biopharmacy and Genetics, Graduate School of Pharmaceutical Sciences, Tohoku University, Sendai, Japan.

Supported by the Foundation for Science and Technology, Portugal (Grant POCTI/CBO/38545/01), and FEDER.

Submitted for publication January 30, 2007; revised June 13, 2007; accepted September 5, 2007.

Disclosure: E.C. Leal, None; A. Manivannan, None; K.-I. Hosoya, None; T. Terasaki, None; J. Cunha-Vaz, None; A.F. Ambrósio, None; J.V. Forrester, None

The publication costs of this article were defrayed in part by page charge payment. This article must therefore be marked "advertisement" in accordance with 18 U.S.C. $\$ 1734$ solely to indicate this fact.

Corresponding author: António Francisco Ambrósio, Center of Ophthalmology of Coimbra, IBILI, Faculty of Medicine, University of Coimbra, Azinhaga de Santa Comba-Celas, 3000-548 Coimbra, Portugal; fambrosio@ibili.uc.pt.
$\mathrm{D}$ iabetic retinopathy (DR) is a leading cause of blindness in working-age adults in the Western world, and chronic hyperglycemia is known to be the prime triggering factor for the development of the disease. ${ }^{1,2}$ Several biochemical abnormalities, including increased aldose reductase activity, elevated nonenzymatic glycation, activation of protein kinase C (PKC), and oxidative stress have been identified in diabetic retinas and contribute to endothelial dysfunction. ${ }^{3-6}$

Oxidative stress induced by diabetes is thought to play a significant role in DR. ${ }^{7-9}$ Reactive oxygen and nitrogen species, including peroxynitrite, a highly reactive oxidant formed by the rapid combination of nitric oxide (NO) with superoxide anion, are increased in the retinas of diabetic rats. ${ }^{10-12}$ This increase has been correlated with increased leukocyte adhesion to retinal vessels and blood-retinal barrier (BRB) breakdown. ${ }^{13-15}$ Increased leukostasis in the early stages of DR occurs through the upregulation of intercellular adhesion molecule-1 (ICAM-1). ${ }^{16}$ ICAM-1 upregulation is mediated by NO, apparently produced by endothelial NO synthase (eNOS) ${ }^{14}$ It is possible that the other NOS isoforms, neuronal and inducible NOS (nNOS and iNOS), are also involved in this process. It is unclear how the different constitutive and inducible NOS isoforms contribute to these events, and the molecular mechanisms of this process are not yet fully understood.

Diabetes-induced BRB breakdown is associated with reduced levels of occludin expression, a tight junction protein, and with its redistribution within the retinal vascular endothelium. ${ }^{17,18}$ However, it is unknown whether NO generated by one NOS isoform or all NOS isoforms is involved in this effect.

We used a customized scanning laser ophthalmoscope (SLO) protocol, ${ }^{19}$ combined with confocal analysis of retinal whole mount preparations to study the role of NO produced in vivo, in leukocyte adhesion to retinal vessels, and in BRB breakdown induced by diabetes in a mouse model of diabetes. Given that an inflammatory component has been associated with $\mathrm{DR}^{20}$ and that NO derived from iNOS may play an important role in DR, we used iNOS KO mice, which can be considered the best approach to study the role of iNOS. In addition, we performed complementary in vitro experiments with a rat retinal endothelial cell line, TR-iBRB $2,{ }^{21}$ to further investigate the mechanism of high glucose-associated leukocyte-endothelial cell adhesion. Our data show that the inducible NOS isoform was the dominant isoform involved in increased leukocyte adhesion to retinal endothelial vessels and BRB breakdown, in the early stages of DR, by a mechanism involving the upregulation of ICAM-1 and the downregulation of tight junction proteins, and mediated by reactive nitrogen species formation and PKC.

\section{Methods}

\section{Animal Models}

Inbred male control (C57BL/6J) and iNOS null (C57BL/6-Nos2tm1 Lau) mice, 12 to 20 weeks old, were obtained from the animal facility at the 
Medical School, Aberdeen University (Scotland, UK). The animals were fed standard laboratory chow and were allowed free access to water in an air-conditioned room with a 12-hour light/12-hour dark cycle. All procedures involving animals were performed in accordance with the ARVO Statement for the Use of Animals in Ophthalmic and Vision Research and in accordance with the regulations of the UK Animal License Act 1986.

Diabetes was induced in C57BL/6J and in iNOS null mice with a single intraperitoneal streptozotocin injection $(160 \mathrm{mg} / \mathrm{kg}$, in saline). Two days later, animals with urine glucose levels (reagent strips for urinalysis; Diastix, Bayer Diagnostics Europe; Dublin, Ireland) higher than $14 \mathrm{mM}$ were considered diabetic. Blood glucose levels were measured (BM-test 1-44; Roche, Basel, Switzerland) before the experiments, and animals with glucose levels higher than $16.7 \mathrm{mM}$ were used.

The following groups of animals were maintained for 2 weeks: control mice, diabetic untreated mice, control mice treated with the NOS inhibitor, $N^{\mathrm{G}}$-nitro-L-arginine methyl ester (L-NAME; $200 \mathrm{mg} / \mathrm{kg}$ intraperitoneally every other day; Sigma, St. Louis, MO), diabetic mice treated with L-NAME (D_L-NAME), iNOS null (KO) mice, and diabetic iNOS null (D_KO) mice.

\section{Leukocyte Labeling}

A cell suspension was obtained from the spleen of a normal C57BL/6J mouse. The cells were resuspended in $20 \mathrm{~mL}$ complete medium (RPMI 1640 supplemented with $10 \%$ [ $\mathrm{vol} / \mathrm{vol}]$ heat-inactivated fetal calf serum [FCS], $1 \%$ sodium pyruvate, $4 \mathrm{mM}$ L-glutamine, $1 \times$ nonessential amino acid [NEAA]; Gibco BRL, Paisley, UK). To label the cells, $2 \times 10^{7}$ cells $/ \mathrm{mL}$ were incubated with $40 \mu \mathrm{g} / \mathrm{mL}$ calcein-AM (C-AM; Molecular Probes Europe, Leiden, The Netherlands) for 30 minutes at $37^{\circ} \mathrm{C}$, as described previously. ${ }^{22} \mathrm{C}$-AM is nontoxic and has no effect on cell adhesion..$^{23}$ The cells were washed, and $1 \times 10^{7}$ leukocytes in $100 \mu \mathrm{L}$ RPMI were adoptively transferred into each mouse through the tail vein.

\section{Leukocyte Adhesion in Whole-Mounted Retinas and BRB Permeability}

Approximately 50 minutes after the infusion of labeled cells, each animal was injected through the tail vein with $100 \mu \mathrm{L}$ of $2 \%$ (wt/vol) Evans blue (Sigma). Evans blue is a dye that binds to the albumin in the blood, thus allowing detection of sites of BRB breakdown, where plasma proteins leak from the vessels. Ten minutes later, the animals were killed with lethal doses of anesthetic (100 $\mu \mathrm{L}$ Euthatal; Merial Animal Health Ltd., Essex, UK). Their eyes were removed and immediately immersed in $2 \%$ (wt/vol) paraformaldehyde (Agar Scientific Ltd., Cambridge, UK) for 2 hours. Retinal whole flat mounts were prepared according to the method of Chan-Ling. ${ }^{24}$ Briefly, the retina was dissected and spread on clean glass slides and mounted in medium (Vectashield; Vector Laboratories, Burlingame, CA) vitreous-side up under coverslips. Retinal flat mounts were analyzed by confocal scanning laser microscopy (LSM 510; Zeiss, Göttingen, Germany) to evaluate the number of leukocytes adhering to retinal vessels and the BRB breakdown sites.

\section{In Vivo Leukocyte Adhesion}

The animals were anesthetized with an anesthetic cocktail of 130 $\mu \mathrm{g} / \mathrm{kg}$ fentanyl (Janssen-Cilag Ltd., Bucks, UK), $10.25 \mathrm{mg} / \mathrm{kg}$ midazolam (Roche), and $3.8 \mathrm{mg} / \mathrm{kg}$ acepromazine (ACP; Novartis Animal Health Ltd., Essex, UK), injected intraperitoneally, producing deep anesthesia for 45 minutes. Pupils were dilated with one drop of $0.5 \%$ (wt/vol) tropicamide (Chauvin Pharmaceuticals Ltd., Essex, UK), and a hard contact lens (clear polymethylmethacrylate [PMMA]; refractive index, 1.51; radius of curvature, $1.7 \mathrm{~mm}$; diameter, $3.2 \mathrm{~mm}$; Cantor \& Nissel, Northamptonshire, UK) was placed on the cornea to obtain a clear view of the eye fundus. Sodium fluorescein $(50 \mu \mathrm{L}, 0.05 \%$ [vol/vol]; Sigma), which has no effect on endothelial cell function, was injected through the tail vein to outline the vessels, followed by the injection of
$1 \times 10^{7}$ C-AM-labeled cells in $100 \mu$ L RPMI. In each animal, the areas adjacent to the optic disc were examined through a custom-built SLO. ${ }^{19}$ Real-time retinal images were captured continuously for the first 30 minutes after injection of labeled cells on DVD-R ( 25 frames/sec) for image analysis using appropriate software, as previously described. ${ }^{25}$ Leukocytes were classified as either free-flowing cells or as adherent cells (sticking cells) if they adhered to the vessels wall for more than 1 second.

\section{Immunolocalization of ICAM-1 and Occludin in Retinal Vessels}

The animals were killed, and the eyes were removed and immersed in $2 \%$ (wt/vol) paraformaldehyde for 2 hours. The retinas were dissected, washed in phosphate-buffered saline (PBS), and permeabilized in $0.3 \%$ Triton X-100 in PBS for 2 hours. The retinas were immersed in blocking solution ( $6 \%$ of normal mouse serum [NMS]) for 30 minutes and incubated overnight with fluorescein isothiocyanate (FITC)-conjugated antibody anti-ICAM-1 (1:100; BD PharMingen, Oxford, UK) or antioccludin (1:100; Zymed Laboratories, San Francisco, CA). FITC-conjugated hamster IgG and mouse IgG, respectively, were used as isotype controls. After incubation, the retinas were washed and mounted on slides for confocal microscopy.

\section{Immunohistochemistry for Nitrotyrosine in Retina}

The animals were killed, and the eyes were frozen in OCT in isopentane at $-80^{\circ} \mathrm{C}$. Transverse sections with $10 \mu \mathrm{m}$ were obtained on a cryostat and collected on polylysine-coated slides and then allowed to air dry for 1 hour. Sections were fixed in acetone for 10 minutes, dried, and washed with PBS. Then they were immersed with $10 \%$ normal rabbit serum (NRbS) in PBS for 30 minutes and incubated overnight at room temperature (RT) with a rabbit anti-nitrotyrosine antibody (1: 100; Upstate Biotechnology, Lake Placid, NY) in 3\% NMS, 0.3\% Triton $\mathrm{X}-100$. Sections were then washed with PBS, incubated with a FITClabeled secondary anti-rabbit antibody (Serotec, Oxford, UK) for 2 hours, washed again, and coverslipped for confocal microscopy.

\section{Confocal Microscopy}

All retinal whole mounts and cryosections were examined for Evans blue and C-AM or for FITC using a confocal scanning laser imaging system fitted with krypton/argon lasers (LSM 510; Zeiss). With the use of dual blue and green fluorescence, the Evans blue stain appeared red and the C-AM or FITC stain appeared green.

\section{Western Blot Analysis}

Mouse retinas were washed with cold PBS and lysed in $150 \mathrm{mM} \mathrm{NaCl}$, $50 \mathrm{mM}$ Tris, $5 \mathrm{mM}$ EGTA, $1 \%$ Triton X-100, 0.5\% deoxycholate, and $0.1 \%$ SDS supplemented with complete mini-protease inhibitor cocktail tablets (Roche). Protein concentration was determined by the bicinchoninic acid (BCA) protein assay kit (Pierce Biotechnology, Rockford, IL), and $30 \mu \mathrm{g}$ protein (when blotting for occludin and ZO-1), $50 \mu \mathrm{g}$ protein (when blotting for eNOS, nNOS, and ICAM-1) or $100 \mu \mathrm{g}$ protein (when blotting for iNOS) from each sample was used for Western blot analysis, after $6 \times$ concentrated sample buffer $(0.5 \mathrm{M}$ Tris, 30\% glycerol, 10\% SDS, $0.6 \mathrm{M}$ dithiothreitol [DTT], $0.012 \%$ bromophenol blue) was added and the samples were heated for 5 minutes at $95^{\circ} \mathrm{C}$. Proteins were separated by electrophoresis on $9 \%$ sodium dodecyl sulfate-polyacrylamide gel electrophoresis (SDS-PAGE) and transferred electrophoretically to polyvinylidene difluoride (PVDF) membranes. The membranes were blocked for 1 hour at RT, in Trisbuffered saline (137 mM NaCl, 20 Tris-HCl, $\mathrm{pH}$ 7.6) containing $0.1 \%$ Tween-20 (TBS-T) and 5\% low-fat milk. Incubation with the primary antibodies rabbit anti-ZO-1 (1:2000), rabbit anti-occludin (1:250; Zymed Laboratories), mouse anti-eNOS (1:1000), mouse anti-nNOS (1:2000), rabbit anti-iNOS (1:2500; BD Transduction Laboratories, San Jose, CA), and goat anti-ICAM-1 (1:200; Santa Cruz Biotechnology) was 
performed overnight at $4^{\circ} \mathrm{C}$. After washing for 1 hour in TBS-T with $0.5 \%$ low-fat milk, the membranes were incubated for 1 hour at RT with alkaline phosphatase-linked secondary antibodies (goat anti-rabbit IgG, goat anti-mouse IgG, or rat anti-goat IgG; 1:20,000 in TBS-T with 1\% low-fat milk; Amersham, Buckinghamshire, UK). Protein immunoreactive bands were visualized using enhanced chemifluorescence (ECF) substrate (ECF Western Blotting Reagent Pack; Amersham), and fluorescence was detected on an imaging system (Storm 860 Gel and Blot Imaging System; Molecular Dynamics, Amersham).

\section{Endothelial Cell Culture}

Rat retinal endothelial cells (TR-iBRB2 cell line) ${ }^{21}$ were cultured in low-glucose DMEM (Gibco BRL, Paisley, UK) containing 10\% heatinactivated fetal bovine serum (FBS), $17.8 \mathrm{mM}$ sodium bicarbonate, 0.1 $\mathrm{mg} / \mathrm{mL}$ streptomycin, and $100 \mathrm{IU} / \mathrm{mL}$ penicillin. Cells were maintained at $33^{\circ} \mathrm{C}$ in a humidified atmosphere of $5 \% \mathrm{CO}_{2}$ /air. Cells were incubated with $24.5 \mathrm{mM}$ glucose (final concentration, $30 \mathrm{mM}$ ) or with 24.5 $\mathrm{mM}$ mannitol (with $5.5 \mathrm{mM}$ glucose; osmotic control) for 24 hours or 4 days. Endothelial cells were also incubated with $100 \mu \mathrm{M} \mathrm{H}_{2} \mathrm{O}_{2}$ or 250 $\mu \mathrm{M}$ NOC-18 (NO donor) for 24 hours and were treated with $50 \mu \mathrm{M}$ L-NAME or with $100 \mathrm{nM} \mathrm{LY379196} \mathrm{(PKC} \mathrm{inhibitor;} \mathrm{a} \mathrm{kind} \mathrm{gift} \mathrm{from} \mathrm{Eli}$ Lilly), as indicated in the figure legends.

\section{Leukocyte Adhesion In Vitro}

With the use of a simple cell-cell adhesion microplate assay, the binding of fluorescently labeled rat (Dark Agouti) leukocytes in suspension to a monolayer of retinal endothelial cells was studied, as previously described. ${ }^{26}$ Briefly, endothelial cells were plated in a 96well microtiter plate at a concentration of $0.25 \times 10^{6}$ cells $/ \mathrm{mL}$ and were allowed to grow to confluence overnight. Leukocytes were harvested and labeled with C-AM, as previously described. The suspension of leukocytes was added to the monolayer of endothelial cells $(2 \times$ $10^{5}$ leukocytes/well) for 90 minutes at $37^{\circ} \mathrm{C}$. After incubation, nonadherent cells were removed by gentle washing with RPMI. The emitted fluorescence (arbitrary units) was measured in a fluorescence plate reader (Fluorite 1000; Dynex Technologies, West Sussex, UK) at an excitation wavelength of $490 \mathrm{~nm}$ and an emission wavelength of 530 $\mathrm{nm}$. Endothelial cells were incubated with the antibody against ICAM-1 ( $40 \mu \mathrm{g} / \mathrm{mL}$ ) 2 hours before the adhesion assay.

\section{Flow Cytometry Analysis of ICAM-1 Expression in Endothelial Cells}

Endothelial cells (TR-iBRB2 cell line) were harvested after gentle tryp$\sin (1 \times$; Sigma $)$ digestion. A total of $1 \times 10^{6}$ cells were incubated with a specific antibody against rat ICAM-1 (1:100; BD PharMingen) in 1\% (vol/vol) FCS and 6\% (vol/vol) NRbS in PBS, at $4^{\circ} \mathrm{C}$ for 30 minutes. After incubation, the cells were washed with $1 \%$ (vol/vol) FCS in PBS and stained with an anti-rat antibody (rabbit IgG; $1: 100$; Sigma) for 30 minutes at $4^{\circ} \mathrm{C}$. Flow cytometry was performed (FACSCalibur; BD Biosciences, San Jose, CA), and the results were analyzed (CellQuest software; BD Biosciences).

\section{Statistical Analysis}

Data are expressed as mean \pm SD. Statistical significance was determined by analysis of variance (ANOVA), followed by Dunnett or Bonferroni post hoc test, as indicated in the figure legends.

\section{Results}

\section{Nitric Oxide Mediates Diabetes-Induced Increase in Leukocyte Adhesion to Retinal Vessels and BRB Breakdown}

The relative contribution of $\mathrm{NO}$, generated from constitutive (eNOS and nNOS) or inducible (iNOS) sources, to the adhesion of leukocytes to retinal vessels induced by diabetes was eval- uated in normal (C57BL/6J) and iNOS knockout (C57BL/6Nos 2 tm 1Lau) mice. Leukocyte adhesion to retinal vessels was assessed in whole-mounted retinas (Figs. 1A, 1B) and in vivo (Fig. 1C). Because we were interested in evaluating the contribution of the retinal vessels and surrounding environment to leukostasis, only normal leukocytes were transferred into mice. The number of leukocytes in whole-mounted retinas was significantly increased in diabetic retinas ( $46 \pm 9$ leukocytes) compared with the retinas isolated from normal mice $(26 \pm 5$ leukocytes; Figs. 1A, 1B, 1D). Treatment of diabetic mice with L-NAME, which inhibits all three NOS isoforms but shows a preference for constitutive isoforms over iNOS, ${ }^{27}$ significantly reduced the number of leukocytes ( $32 \pm 4$ leukocytes) compared with diabetic animals (Figs. 1A, 1B, 1D). Treatment of control animals with L-NAME did not cause any significant change. Similar results were obtained in in vivo experiments. Diabetes induced an increase in the number of adherent leukocytes $(73 \pm 17$ in the retinal vessels located near the optic disc; Figs. 1C, 1E) compared with control retinas $(31 \pm 9$ adherent leukocytes). L-NAME treatment reduced the number of adherent leukocytes in diabetic retinas to $37 \pm 9$ (Fig. 1E), and no effect was observed with L-NAME treatment in normal mouse retinas. In the retinas of diabetic iNOS KO mice, significantly fewer leukocytes were observed in whole-mounted retinas and SLO experiments $(31 \pm 4$ and $47 \pm 10$ leukocytes, respectively) than in retinas of diabetic mice ( $46 \pm 9$ and $73 \pm$ 17 leukocytes, respectively; Figs. 1D, 1E).

The breakdown of the BRB induced by diabetes was evaluated by analyzing the leakage of Evans blue from retinal vessels (Fig. 1A). Retinas of control mice revealed normal retinal vessel architecture with no detectable leakage. After 2 weeks of diabetes, BRB breakdown was evidenced by extensive Evans blue leakage from retinal vessels into the tissue parenchyma. In diabetic mice treated with L-NAME and in diabetic iNOS KO mice, a decrease in dye leakage was clearly observed (Fig. 1A).

\section{Nitric Oxide Mediates Diabetes-Induced Increase in ICAM-1 Retinal Expression}

It has been shown that the adhesion of leukocytes to retinal vessels is mediated, at least in part, by ICAM-1, which is upregulated in diabetic retinal endothelial cells. Therefore, we sought to determine whether NO-mediated leukocyteendothelial cell adhesion in diabetic mice was caused by ICAM-1 upregulation. Protein expression levels of ICAM-1 in diabetic retinas increased to $159.7 \% \pm 38.3 \%$ of the control, and this effect was inhibited by treatment with L-NAME $(109.5 \% \pm 14.6 \%$ of the control; Fig. $2 \mathrm{~A})$. In diabetic iNOS KO mice, ICAM-1 expression levels were similar to those found in control retinas $(108.4 \% \pm 29.0 \%$ of control; Fig. 2B). Protein expression levels of ICAM-1 were not altered in the retinas of nondiabetic animals treated with L-NAME or in iNOS KO mice.

In addition, the immunoreactivity of ICAM-1 increased in retinal vessels of diabetic animals, and this effect was inhibited by L-NAME treatment. The immunoreactivity of ICAM- 1 in the retinas of nondiabetic and diabetic iNOS KO mice was similar to the immunoreactivity observed in the retinas of control mice (Fig. 2C).

\section{Nitric Oxide Mediates Diabetes-Induced Downregulation of the Tight Junction Proteins Occludin and ZO-1}

To determine whether increased retinal vessel leakage, observed in diabetic mice, was caused by alterations in the content of tight junction proteins, the expression of occludin and ZO-1, two important tight junction proteins, was analyzed by Western blotting and immunocytochemistry in retinal homog- 
A

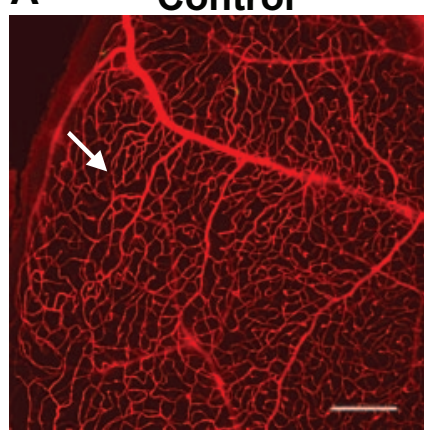

B

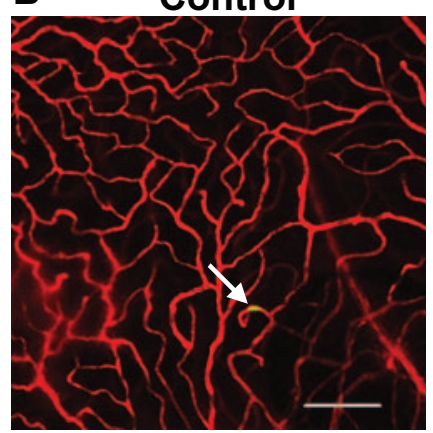

C Diabetic (SLO) D

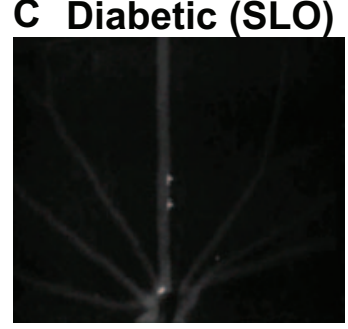

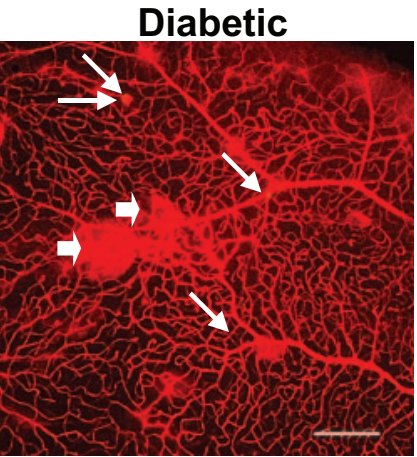

Diabetic
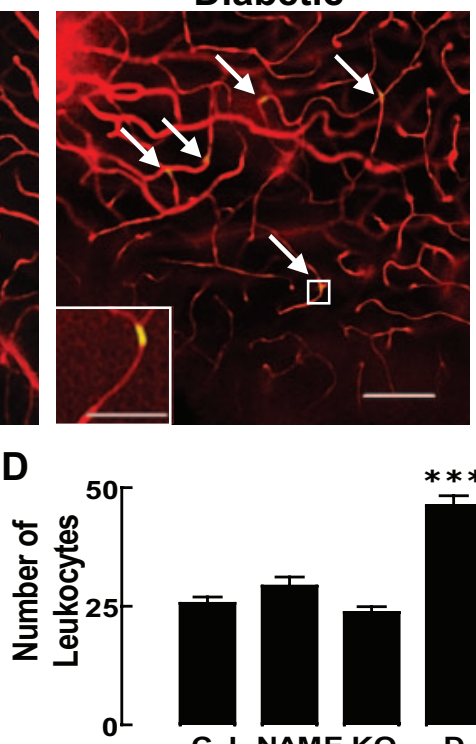

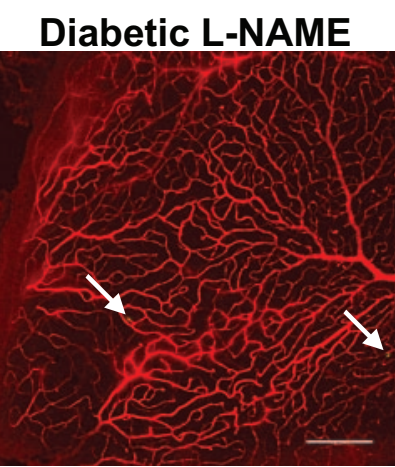

Diabetic L-NAME

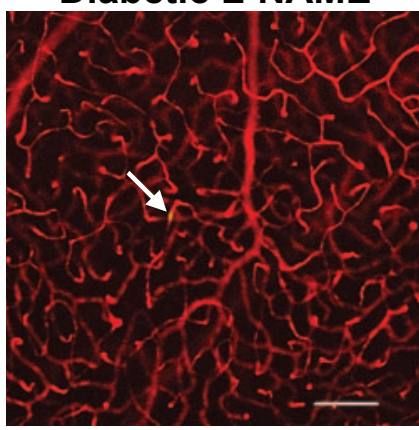

E

\section{Diabetic iNOS KO}

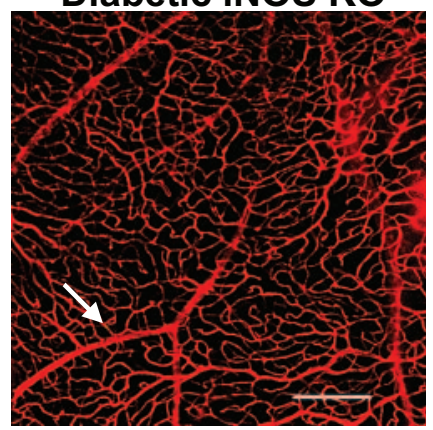

Diabetic iNOS KO

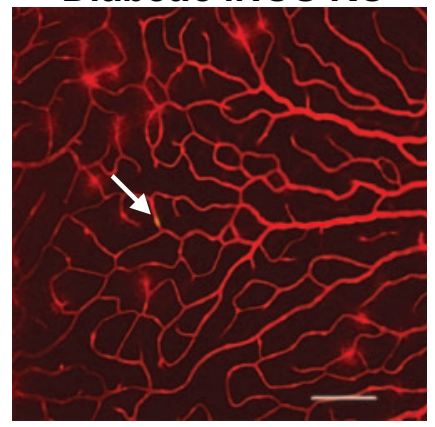

FIGURE 1. Effect of diabetes on retinal leukostasis and BRB breakdown: involvement of NO. Leukocytes stained with C-AM, isolated from the spleens of control mice, were injected, through the tail veins of mice in different groups: control (C), treated with L-NAME (L-NAME), diabetic (D), diabetic treated with L-NAME (D_L-NAME), iNOS KO (KO), and diabetic iNOS KO (D_KO). (A) Representative images of accumulating leukocytes and vessel leakage in whole-mounted retinas. Evans blue (red) injected through the tail vein 10 minutes before animal kill, outlines retinal vessels, allowing the detection of BRB breakdown. Small arrows: trapped leukocytes (green). Large arrows: vessel leakage. Scale bar, $200 \mu \mathrm{m}$. (B) Representative images of accumulating leukocytes at higher magnification. Scale bar, $100 \mu \mathrm{m}$. (C) Representative SLO image of a diabetic retina with adherent leukocytes. (D) Quantification of leukocytes trapped in whole-mounted retinas. Data represent the number of leukocytes in the entire retina in each condition tested, as indicated below the bars. (E) Quantification of adherent leukocytes in vivo using an SLO. Data are presented as mean \pm SD of at least six mice. ${ }^{*} P<0.05$ and ${ }^{* * *} P<0.001$ compared with control mice; Dunnett posttest. \#\#\#P<0.001 compared with diabetic mice; Bonferroni posttest.

enates and retina whole mounts, respectively. Occludin and ZO-1 protein levels decreased to $81.1 \% \pm 9.3 \%$ and $74.0 \%$ $\pm 10.0 \%$ of the control, respectively, in diabetic retinas (Figs. 3A, 3B). Treatment of diabetic mice with L-NAME prevented the decrease in occludin and $\mathrm{ZO}-1$ protein levels induced by diabetes, indicating that NO mediates the downregulation of tight junction proteins and could thus explain in part the breakdown in BRB function. Similarly, the reduction in the protein levels of occludin and $\mathrm{ZO}-1$ induced by diabetes was prevented in diabetic iNOS KO mice (Figs. 3C, 3D).

In control mice, occludin was strongly expressed in endothelial cell membranes of retinal vessels, whereas it was markedly reduced and sometimes absent or more diffusely distributed in diabetic mice. This dysregulation of occludin expression was prevented by treatment with L-NAME and in iNOS KO diabetic mice (Fig. 3E). Because ZO-1 is also expressed in the cytosol of neural cells, it was difficult to evaluate changes of this protein in retinal vessels (not shown).

\section{Nitric Oxide Mediates Diabetes-Induced Upregulation of Nitric Oxide Synthase Isoforms}

Feedback upregulation of eNOS is mediated by NO itself. ${ }^{14}$ Therefore, we examined protein expression levels of the three NOS isoforms (eNOS, nNOS, iNOS) in diabetic mice by quantitative Western blotting of mouse retinal homogenates. Diabetes increased the protein levels of eNOS $(151.3 \% \pm 39.4 \%$ of the control), nNOS $(143.8 \% \pm 16.2 \%$ of the control), and iNOS $(174.6 \% \pm 67.5 \%$ of the control; Figs. $4 \mathrm{~A}-\mathrm{C})$. Treatment with L-NAME inhibited the increase in protein levels of NOS isoforms, particularly those of eNOS $(106.3 \% \pm 36.0 \%$ of the control; Fig. 4A) and iNOS (113.7\% $\pm 46.5 \%$ of the control; Fig. 4C), but did not cause a significant reduction of nNOS protein levels $(124.7 \% \pm 18.8 \%$ of the control; Fig. $4 \mathrm{~B})$. These results suggest that NO itself upregulates the expression of NOS isoforms in a positive feedback mechanism. Treatment of nondiabetic mice with L-NAME did not alter the expression levels of 
FIGURE 2. Effect of diabetes on the expression of ICAM-1: involvement of NO. ICAM-1 expression was determined in retinal homogenates by Western blotting $(\mathbf{A}, \mathbf{B})$ and in retina whole mounts by immunohistochemistry (C). The immunoreactivity of ICAM-1 was determined in the retinas of control and diabetic mice, treated or not treated with L-NAME, and in nondiabetic and diabetic iNOS $\mathrm{KO}$ mice, as indicated below the bars $(\mathbf{A}, \mathbf{B})$ or in the images $(\mathbf{C})$. Scale bar, $100 \mu \mathrm{m}$. Western blots are representative of each group of mice, composed of at least six animals. Results are presented as percentage of control and represent the mean $\pm \mathrm{SD}$. ${ }^{* *} P<0.01$ compared with control mice; Dunnett posttest

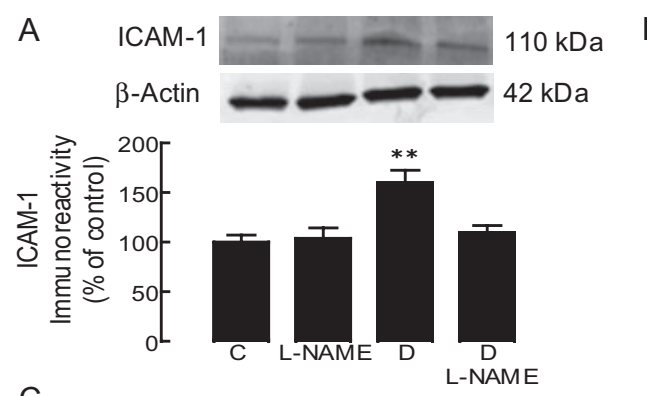

B

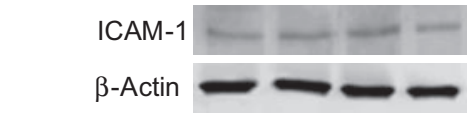

$110 \mathrm{kDa}$
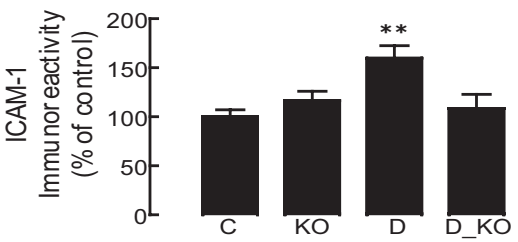

C
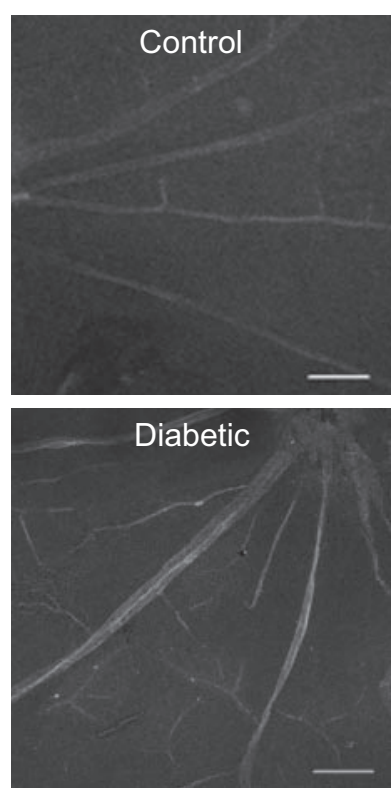
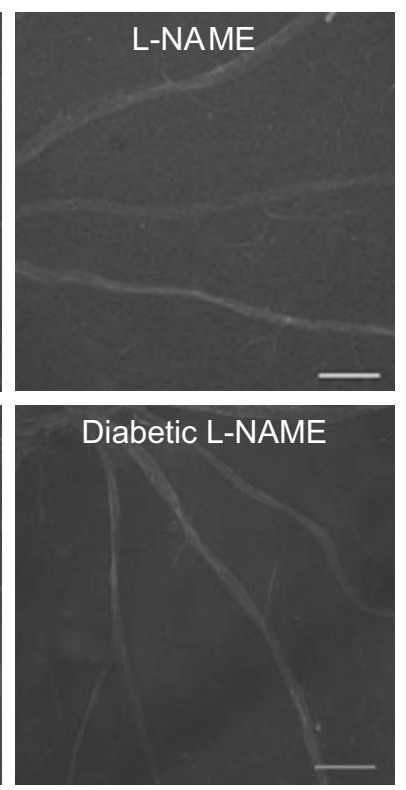
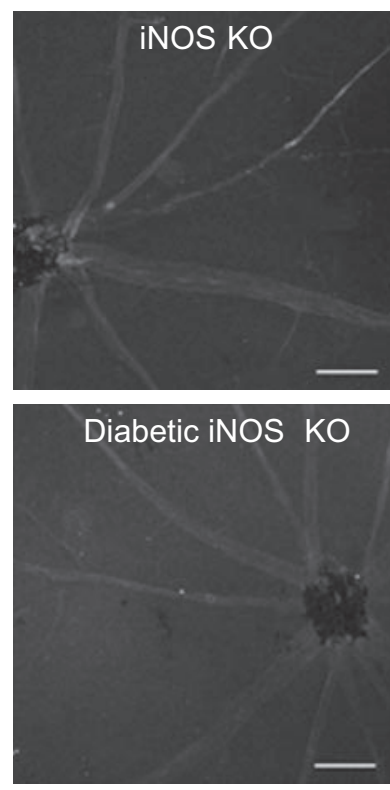

the three NOS isoforms. The protein levels of NOS isoforms in the retinas of iNOS KO mice, eNOS and nNOS, were not significantly different $(116.5 \% \pm 36.4 \%$ and $130.2 \% \pm 13.4 \%$ of the control, respectively) from the eNOS and nNOS protein levels detected in the retinas of control mice (Figs. 4D, 4E). In addition, the induction of diabetes in iNOS KO mice did not significantly increase the protein levels of eNOS and nNOS, though they were significantly different from those of nondiabetic controls $(148.9 \% \pm 23.5 \%$ and $150.5 \% \pm 6.5 \%$ of the control, respectively).
A

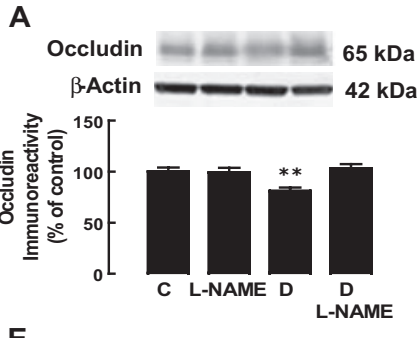

B

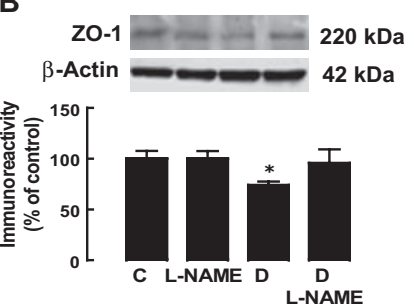

C
D
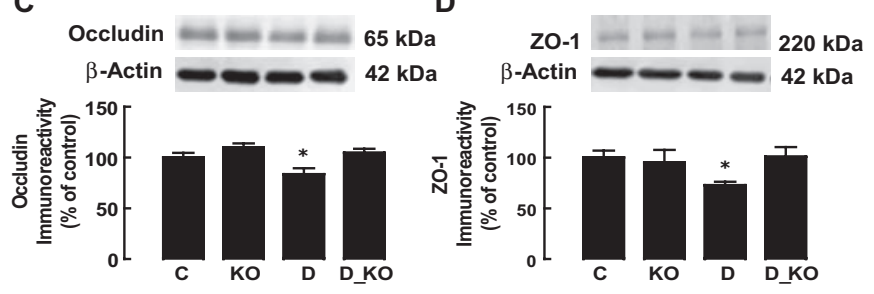

E
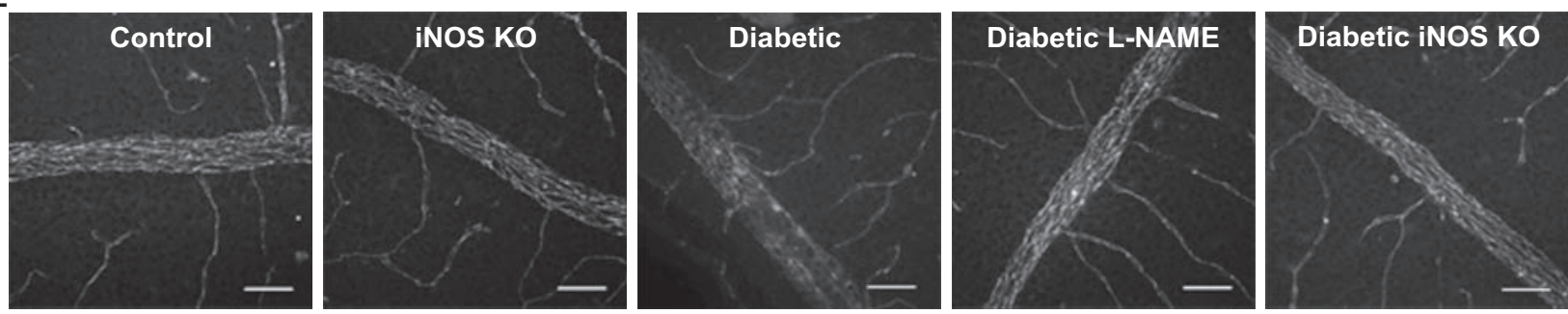

FIGURE 3. Effect of diabetes on the expression of occludin and ZO-1 in the mouse retina: involvement of NO. Occludin (A, C) and ZO-1 (B, D) expression were analyzed by Western blotting in retinal homogenates obtained from control and diabetic mice, treated or not treated with L-NAME, and in nondiabetic and diabetic iNOS KO mice, as indicated below bars. Western blots are representative of each group of mice, composed of at least six animals. (E) Representative images of occludin immunostaining in mouse retinas, obtained from different groups of mice, as indicated in the images. Scale bar, $50 \mu \mathrm{m}$. Results are presented as percentage of control and represent the mean \pm SD. ${ }^{*} P<0.05$ and ${ }^{* * *} P<0.01$ compared with control mice; Dunnett posttest. 
A

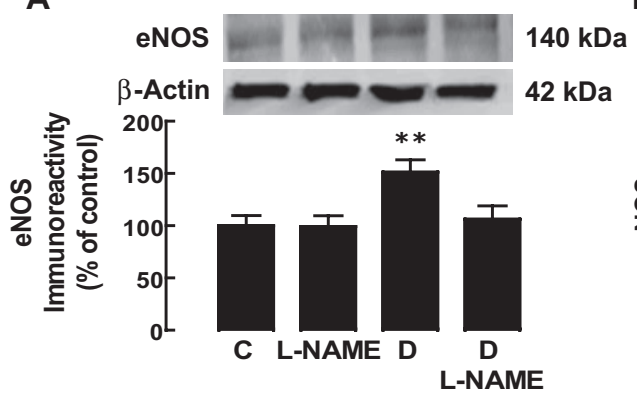

C
B

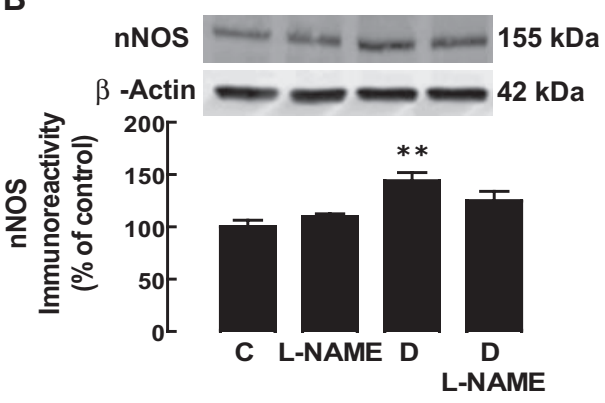

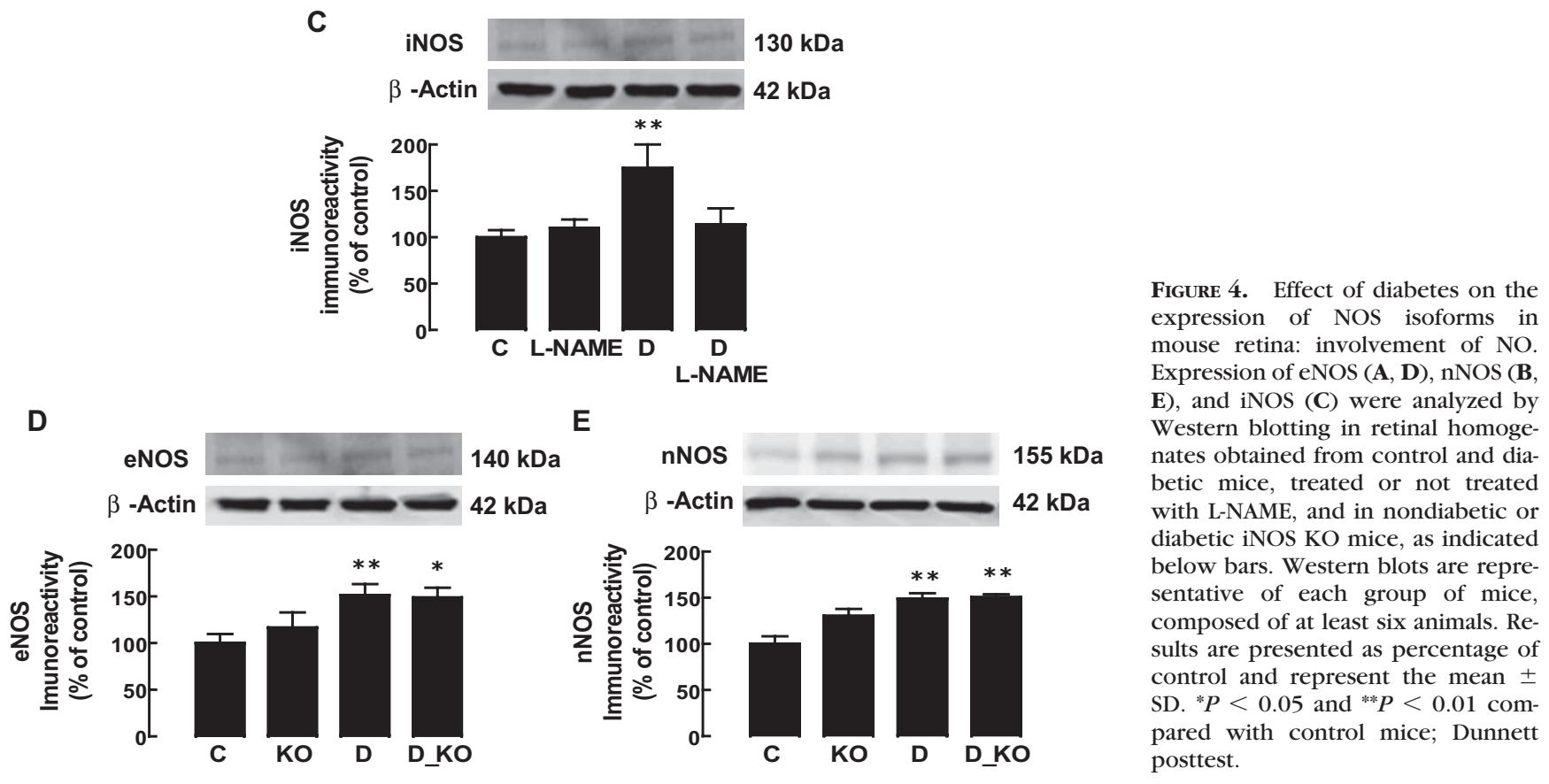

\section{Diabetes Increases Protein Nitration in the Retina}

Peroxynitrite $\left(\mathrm{ONOO}^{-}\right)$is a short-lived molecule that results from the reaction of $\mathrm{NO}$ with superoxide and can attack a wide range of biological molecules. Peroxynitrite produces stable nitration of protein tyrosine residues, impairing protein function. ${ }^{28}$ Because the formation of nitrotyrosine is correlated with NO production, determining the nitrotyrosine content is usually considered an indirect measure of NO production. Nitrotyrosine content was assessed by immunohistochemistry in mouse retinas (Fig. 5). Nitrotyrosine immunostaining increased in diabetic retinas, namely in ganglion cell layer (GCL) and outer plexiform layer (OPL), and treatment with L-NAME prevented the increase in nitrotyrosine formation. The induction of diabetes in iNOS KO mice did not increase nitrotyrosine formation.

\section{High Glucose Level and Oxidative/Nitrosative Stress Increase In Vitro Leukocyte Adhesion to Retinal Endothelial Cells: Involvement of NO and PKC}

The adhesion of leukocytes to retinal endothelial cells was also evaluated using an in vitro assay. The leukocytes used in these experiments were obtained from the spleens of normal rats. High glucose (30 mM, 4 days) increased leukocyte adhesion to
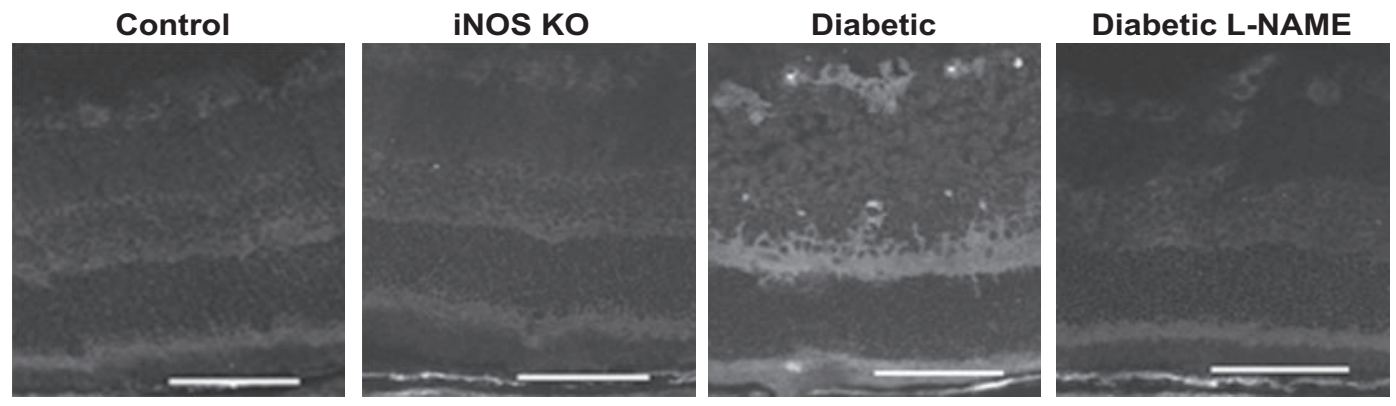

\section{Diabetic iNOS KO}

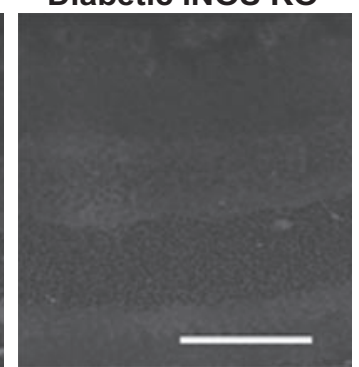

FIGURE 5. Effect of diabetes on nitrotyrosine formation in mouse retina: involvement of NO. Representative images of nitrotyrosine immunostaining in mouse retinas, obtained from different groups of mice, as indicated. Scale bar, $100 \mu \mathrm{m}$. 
A

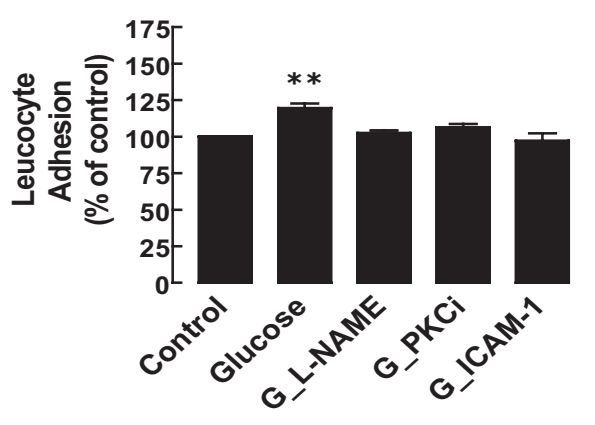

B

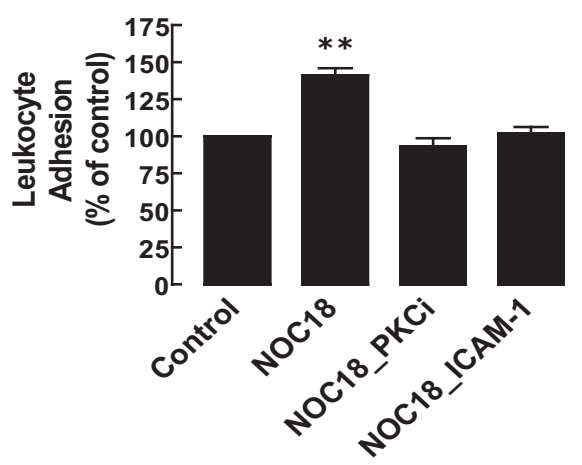

C

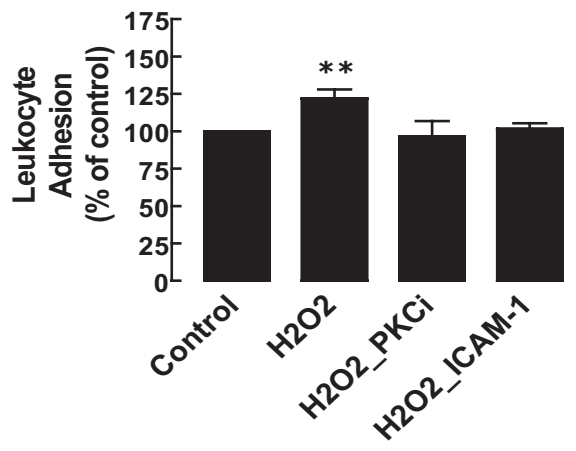

FIGURE 6. Quantification of in vitro leukocyte adhesion to endothelial cells. Leukocytes isolated from the spleens of normal rats were stained with C-AM and then incubated with retinal endothelial cells for 90 minutes. Leukocyte adhesion was quantified by a fluorometric assay. (A) Endothelial cells exposed to high glucose ( $30 \mathrm{mM}, \mathrm{G})$, for 4 days, were treated with L-NAME (50 $\mu \mathrm{M})$, a PKC inhibitor (LY379196, $100 \mathrm{nM})$, or with an antibody against ICAM-1 $(40 \mu \mathrm{g} / \mathrm{mL})$. (B, C) Endothelial cells exposed to NOC-18 $(250 \mu \mathrm{M})$ or $\mathrm{H}_{2} \mathrm{O}_{2}(100 \mu \mathrm{M})$ for 24 hours were treated with a PKC inhibitor (LY379196, $100 \mathrm{nM}$ ) or with an antibody against ICAM-1. Results are presented as percentage of control and represent the mean \pm SD of at least four independent experiments, made in triplicate. ${ }^{* *} P<0.01$, compared with control; Dunnett posttest.

endothelial cells (Fig. 6A; $119.5 \% \pm 10.1 \%$ of the control), and this effect was prevented by L-NAME. The incubation of endothelial cells with an inhibitor of PKC (LY379196, $100 \mathrm{nM}$ ) or with an antibody against ICAM-1, which was added to block ICAM-1 2 hours before the leukocyte adhesion assay, also prevented the increase in leukocyte adhesion induced by high glucose. L-NAME, LY379196, or the antibody against ICAM-1 did not alter leukocyte adhesion to control endothelial cells (not shown).

Exposure of retinal endothelial cells to a NO donor, NOC18 , or $\mathrm{H}_{2} \mathrm{O}_{2}$ for 24 hours also increased the adhesion of leukocytes to endothelial cells $(141.0 \% \pm 9.7 \%$ and $121.8 \% \pm$ $12.5 \%$ of the control, respectively; Figs. 6B, 6C). These effects were prevented by LY379196 or by the antibody against ICAM-1 (Figs. 6B, 6C), indicating a general effect of free radicals on ICAM-1 upregulation.

The effect of high glucose, NOC-18, or $\mathrm{H}_{2} \mathrm{O}_{2}$ on the expression of ICAM-1 in retinal endothelial cell membranes was analyzed by flow cytometry. High glucose (24-hour or 4-day exposure) significantly increased ICAM-1 levels in endothelial cells $(122.0 \% \pm 12.4 \%$ and $121.0 \% \pm 3.4 \%$ of the control, respectively; Fig. 7A). Similar results were obtained when endothelial cells were exposed to NOC-18 or $\mathrm{H}_{2} \mathrm{O}_{2}$ for 12 or 24 hours (Fig. 7B).

\section{Discussion}

Diabetes increases leukocyte adhesion to retinal vessels and induces the breakdown of $\mathrm{BRB},{ }^{29,30}$ and it has been shown that
NO can mediate these events. ${ }^{13,14} \mathrm{NO}$ is synthesized by constitutive and inducible NOS isoforms; hence, it is important to understand the relevance of the different NOS isoforms in this process and the mechanisms involved. Previous studies have suggested that constitutive NOS mediates those early events in $\mathrm{DR}^{13,14}$; however, given that an inflammatory component has been shown to occur in early $\mathrm{DR},{ }^{10,31,32}$ the iNOS isoform could also be an important potential contributor to NO generation at this interface. iNOS mediates retinal apoptosis in late DR events such as ischemic proliferative retinopathy, ${ }^{33}$ and it modulates progenitor and resident endothelial cell behavior in galactosemia. ${ }^{34}$ Given that iNOS is involved in inflammation, a selective deletion of iNOS, leading to a decrease in leukostasis and in BRB breakdown in diabetes, would support its involvement in these early pathogenic processes. Others have shown that aminoguanidine, used as an iNOS inhibitor, can prevent a diabetes-mediated increase in nitrosative stress, iNOS expression, and NOS activity in the retina. ${ }^{11,35,36}$ However, aminoguanidine is not the best tool to evaluate the role of iNOS because it is only effective in vivo at high doses. ${ }^{27}$ In addition, it is not specific for iNOS because it also inhibits the formation of advanced glycosylation products (AGEs) thought to play a major role in the pathogenesis of diabetic complications. ${ }^{37,38}$ Thus, the use of iNOS KO mice can be considered an excellent tool to study the role of iNOS in DR.

We have found that NO derived from iNOS is strongly involved in the induction of early vascular changes, suggesting that iNOS has a key role in early DR. Constitutive NOS isoforms may have similar effects, especially when tested in vitro, but
A

Figure 7. Effect of high glucose, NOC-18, or $\mathrm{H}_{2} \mathrm{O}_{2}$ on ICAM-1 expression in retinal endothelial cells. ICAM-1 expression was measured by flow cytometry. (A) Endothelial cells were exposed to $30 \mathrm{mM}$ glucose for 24 hours or 4 days. (B) Endothelial cells were exposed to NOC-18 (250 $\mu \mathrm{M})$ or $\mathrm{H}_{2} \mathrm{O}_{2}(100 \mu \mathrm{M})$ for 12 or 24 hours. Data are presented as percentage of control and represent the mean $\pm \mathrm{SD}$ of at least four independent experiments. ${ }^{*} P<0.05$ and ${ }^{* *} P<0.01$ compared with control; Dunnett posttest.

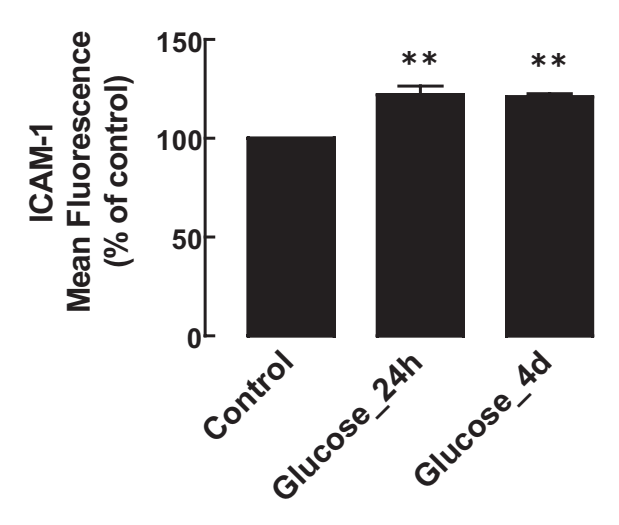

B

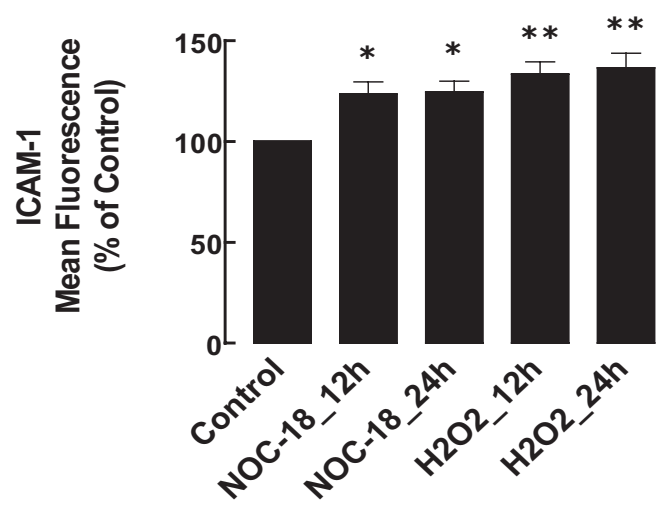


they have no significant additional or synergistic effects in vivo because in the presence of constitutive NOS, but deleted iNOS, diabetes-induced leukostasis and BRB breakdown is significantly inhibited or even prevented. Indeed, despite the fact that constitutive NOS is upregulated in diabetic iNOS KO mice, diabetic-induced leukostasis and BRB breakdown is largely prevented. However, the involvement of constitutive NOS cannot be completely ruled out because all NOS isoforms were upregulated in the retinas of diabetic mice.

Nitric oxide, in the presence of superoxide, rapidly forms peroxynitrite, a strong oxidant that can be generated in several cell types (Müller cells, astrocytes, microglial cells, neurons, endothelial cells). Peroxynitrite reacts with proteins, leading to the addition of a nitro group to tyrosine residues to form nitrotyrosine. In diabetic rat retinas, nitrotyrosine formation was detected in the retinal vasculature and where blood vessels are found (GCL, IPL, OPL). ${ }^{11,39}$ We also detected nitrotyrosine formation in GCL and OPL. Sites of nitrotyrosine deposition are determined by superoxide formation because superoxide cannot cross cell membranes. ${ }^{40}$ In contrast, NO can freely cross cell membranes and can exert action in other cells. Thus, peroxynitrite may be generated in nearly all cell types in the retina during diabetes. The blood-retinal barrier is influenced by Müller cells and astrocytes ${ }^{18,41}$ but may be affected indirectly by microglial cells and neurons through released factors. ${ }^{42,43}$ Therefore, the observed effects in retinal vasculature might be attributed not only to alterations in endothelial cells but also to the dysfunction of other cell types.

The mechanism by which NO mediates the effects of diabetes on the retinal vasculature was also studied. Our data revealed that the major effect of NO production is to upregulate ICAM-1 in endothelial cells, which thus promotes leukocyte adhesion. Conversely, NO promoted the downregulation of the tight junction proteins occludin and $\mathrm{ZO}-1$, leading to the breakdown of BRB. Other studies, in pulmonary epithelium and in kidney cells, showed that NO mediates the downregulation of tight junction protein expression and the irregular tight junction staining. ${ }^{44,45}$ Our in vitro data also suggested that NO is responsible for the high glucose-induced ICAM-1 increase and its downstream effect on leukocyte adhesion. Indeed this may be a general effect of free radicals, in which PKC is also involved.

Based on our findings we hypothesize that the mechanism of damage to retinal vessels in diabetes is an initial glucosemediated injury to the endothelium, leading to an increase in NO production by the upregulation of constitutive and inducible NOS expression, which then induces an upregulation in ICAM-1 expression and an increase in leukocyte adhesion. Our results indicate that iNOS is mainly involved. Therefore, the process can be amplified by NO released through iNOS, which produces high amounts of NO, further compounding the damage to the endothelium. This leads progressively to greater areas of small vessel and capillary closure, which over time produce increasingly large areas of retinal ischemia, despite attempts by the retina to induce new capillary formation and reperfusion.

\section{Acknowledgment}

The authors thank Mary Cotter for the permission to use diabetic mice.

\section{References}

1. The effect of intensive treatment of diabetes on the development and progression of long-term complications in insulin-dependent diabetes mellitus: the Diabetes Control and Complications Trial Research Group. N Engl J Med. 1993;329:977-986.

2. Intensive blood-glucose control with sulphonylureas or insulin compared with conventional treatment and risk of complications in patients with type 2 diabetes (UKPDS 33): UK Prospective Diabetes Study (UKPDS) Group. Lancet. 1998;352:837-853.

3. Chakrabarti S, Cukiernik M, Hileeto D, Evans T, Chen S. Role of vasoactive factors in the pathogenesis of early changes in diabetic retinopathy. Diabetes Metab Res Rev. 2000;16:393-407.

4. Kowluru RA. Diabetes-induced elevations in retinal oxidative stress, protein kinase $\mathrm{C}$ and nitric oxide are interrelated. Acta Diabetol. 2001;38:179-185.

5. Stitt AW, Li YM, Gardiner TA, Bucala R, Archer DB, Vlassara H. Advanced glycation end products (AGEs) co-localize with AGE receptors in the retinal vasculature of diabetic and of AGE-infused rats. Am J Pathol. 1997; 150:523-531.

6. Xia P, Inoguchi T, Kern TS, Engerman RL, Oates PJ, King GL. Characterization of the mechanism for the chronic activation of diacylglycerol-protein kinase $\mathrm{C}$ pathway in diabetes and hypergalactosemia. Diabetes. 1994;43:1122-1129.

7. Baynes JW. Role of oxidative stress in development of complications in diabetes. Diabetes. 1991;40:405-412.

8. Jennings PE, McLaren M, Scott NA, Saniabadi AR, Belch JJ. The relationship of oxidative stress to thrombotic tendency in type 1 diabetic patients with retinopathy. Diabet Med. 1991;8:860-865.

9. Kowluru RA, Tang J, Kern TS. Abnormalities of retinal metabolism in diabetes and experimental galactosemia, VII: effect of long-term administration of antioxidants on the development of retinopathy. Diabetes. 2001;50:1938-1942.

10. Carmo A, Cunha-Vaz JG, Carvalho AP, Lopes MC. Effect of cyclosporin-A on the blood-retinal barrier permeability in streptozotocin-induced diabetes. Mediators Inflamm. 2000;9:243-248.

11. Du Y, Smith MA, Miller CM, Kern TS. Diabetes-induced nitrative stress in the retina, and correction by aminoguanidine. $J$ Neurochem. 2002;80:771-779.

12. Kowluru RA, Engerman RL, Kern TS. Abnormalities of retinal metabolism in diabetes or experimental galactosemia, VIII: prevention by aminoguanidine. Curr Eye Res. 2000;21:814-819.

13. El-Remessy AB, Behzadian MA, Abou-Mohamed G, Franklin T, Caldwell RW, Caldwell RB. Experimental diabetes causes breakdown of the blood-retina barrier by a mechanism involving tyrosine nitration and increases in expression of vascular endothelial growth factor and urokinase plasminogen activator receptor. $A m J$ Patbol. 2003;162:1995-2004.

14. Joussen AM, Poulaki V, Qin W, et al. Retinal vascular endothelial growth factor induces intercellular adhesion molecule-1 and endothelial nitric oxide synthase expression and initiates early diabetic retinal leukocyte adhesion in vivo. Am J Patbol. 2002;160: 501-509

15. Sugawara R, Hikichi T, Kitaya N, et al. Peroxynitrite decomposition catalyst, FP15, and poly(ADP-ribose) polymerase inhibitor, PJ34, inhibit leukocyte entrapment in the retinal microcirculation of diabetic rats. Curr Eye Res. 2004;29:11-16.

16. Miyamoto K, Khosrof S, Bursell SE, et al. Prevention of leukostasis and vascular leakage in streptozotocin-induced diabetic retinopathy via intercellular adhesion molecule-1 inhibition. Proc Natl Acad Sci USA. 1999;96:10836-10841.

17. Antonetti DA, Barber AJ, Khin S, Lieth E, Tarbell JM, Gardner TW. Vascular permeability in experimental diabetes is associated with reduced endothelial occludin content: vascular endothelial growth factor decreases occludin in retinal endothelial cells: Penn State Retina Research Group. Diabetes. 1998;47:1953-1959.

18. Barber AJ, Antonetti DA, Gardner TW. Altered expression of retinal occludin and glial fibrillary acidic protein in experimental diabetes: the Penn State Retina Research Group. Invest Opbthalmol Vis Sci. 2000;41:3561-3568.

19. Manivannan A, Sharp PF, Phillips RP, Forrester JV. Digital fundus imaging using a scanning laser ophthalmoscope. Physiol Meas. 1993;14:43-56.

20. Joussen AM, Poulaki V, Le ML, et al. A central role for inflammation in the pathogenesis of diabetic retinopathy. FASEB J. 2004;18: $1450-1452$.

21. Hosoya K, Tomi M, Ohtsuki S, et al. Conditionally immortalized retinal capillary endothelial cell lines (TR-iBRB) expressing differentiated endothelial cell functions derived from a transgenic rat. Exp Eye Res. 2001;72:163-172. 
22. $\mathrm{Xu} \mathrm{H}$, Manivannan A, Goatman KA, et al. Improved leukocyte tracking in mouse retinal and choroidal circulation. Exp Eye Res. 2002;74:403-410.

23. Abbitt KB, Rainger GE, Nash GB. Effects of fluorescent dyes on selectin and integrin-mediated stages of adhesion and migration of flowing leukocytes. J Immunol Methods. 2000;239:109-119.

24. Chan-Ling T. Glial, vascular, and neuronal cytogenesis in wholemounted cat retina. Microsc Res Tech. 1997;36:1-16.

25. Hossain $P$, Liversidge $J$, Cree $M J$, et al. In vivo cell tracking by scanning laser ophthalmoscopy: quantification of leukocyte kinetics. Invest Ophthalmol Vis Sci. 1998;39:1879-1887.

26. Braut-Boucher F, Pichon J, Rat P, Adolphe M, Aubery M, Font J. A non-isotopic, highly sensitive, fluorimetric, cell-cell adhesion microplate assay using calcein AM-labeled lymphocytes. I Immunol Methods. 1995;178:41-51.

27. Southan GJ, Szabo C. Selective pharmacological inhibition of distinct nitric oxide synthase isoforms. Biochem Pharmacol. 1996; 51:383-394.

28. Halliwell $\mathrm{B}$. What nitrates tyrosine? Is nitrotyrosine specific as a biomarker of peroxynitrite formation in vivo? FEBS Lett. 1997;411: 157-160.

29. Miyamoto K, Hiroshiba N, Tsujikawa A, Ogura Y. In vivo demonstration of increased leukocyte entrapment in retinal microcirculation of diabetic rats. Invest Opbthalmol Vis Sci. 1998;39:21902194.

30. Sander B, Larsen M, Engler C, Lund-Andersen H, Parving HH. Early changes in diabetic retinopathy: capillary loss and blood-retina barrier permeability in relation to metabolic control. Acta Ophthalmol (Copenb). 1994;72:553-559.

31. do Carmo A, Lopes C, Santos M, Proenca R, Cunha-Vaz J, Carvalho AP. Nitric oxide synthase activity and L-arginine metabolism in the retinas from streptozotocin-induced diabetic rats. Gen Pharmacol. 1998;30:319-324.

32. Joussen AM, Huang S, Poulaki V, et al. In vivo retinal gene expression in early diabetes. Invest Opbthalmol Vis Sci. 2001;42:30473057.

33. Sennlaub F, Courtois Y, Goureau O. Inducible nitric oxide synthase mediates retinal apoptosis in ischemic proliferative retinopathy. J Neurosci. 2002;22:3987-3993.

34. Ellis EA, Sengupta N, Caballero S, Guthrie SM, Mames RN, Grant MB. Nitric oxide synthases modulate progenitor and resident en- dothelial cell behavior in galactosemia. Antioxid Redox Signal. 2005; 7:1413-1422.

35. Du Y, Sarthy VP, Kern TS. Interaction between NO and COX pathways in retinal cells exposed to elevated glucose and retina of diabetic rats. Am J Physiol Regul Integr Comp Physiol. 2004;287: $\mathrm{R} 735-\mathrm{R} 741$.

36. Carmo A, Cunha-Vaz JG, Carvalho AP, Lopes MC. Nitric oxide synthase activity in retinas from non-insulin-dependent diabetic Goto-Kakizaki rats: correlation with blood-retinal barrier permeability. Nitric Oxide. 2000;4:590-596.

37. Wautier JL, Guillausseau PJ. Advanced glycation end products, their receptors and diabetic angiopathy. Diabetes Metab. 2001;27: 535-542.

38. Rahbar S, Kumar Yernini K, Scott S, Gonzales N, Lalezari I. Novel inhibitors of advanced glycation endproducts. Biochem Biophys Res Commun. 1999;262:651-656.

39. El-Remessy AB, Abou-Mohamed G, Caldwell RW, Caldwell RB. High glucose-induced tyrosine nitration in endothelial cells: role of eNOS uncoupling and aldose reductase activation. Invest Ophthalmol Vis Sci. 2003;44:3135-3143.

40. Espey MG, Miranda KM, Feelisch M, et al. Mechanisms of cell death governed by the balance between nitrosative and oxidative stress. Ann NY Acad Sci. 2000;899:209-221.

41. Tout S, Chan-Ling T, Hollander H, Stone J. The role of Muller cells in the formation of the blood-retinal barrier. Neuroscience. 1993; 55:291-301.

42. Barber AJ. A new view of diabetic retinopathy: a neurodegenerative disease of the eye. Prog Neuropsychopharmacol Biol Psychiatry. 2003;27:283-290.

43. Hughes EH, Schlichtenbrede FC, Murphy CC, et al. Generation of activated sialoadhesin-positive microglia during retinal degeneration. Invest Opbthalmol Vis Sci. 2003;44:2229-2234.

44. Han X, Fink MP, Uchiyama T, Yang R, Delude RL. Increased iNOS activity is essential for pulmonary epithelial tight junction dysfunction in endotoxemic mice. Am J Physiol Lung Cell Mol Physiol. 2004;286:L259-L267.

45. Somosy Z, Bognar G, Horvath G, Koteles GJ. Role of nitric oxide, CAMP and CGMP in the radiation induced changes of tight junctions in Madin-Darby canine kidney cells. Cell Mol Biol (Noisy-legrand). 2003;49:59-63. 